\title{
Diagnostic dilatation and curettage: is it used appropriately?
}

\author{
Angela Coulter, Anne Klassen, Ian Z MacKenzie, Klim McPherson
}

Abstract

Objective-To determine patterns of use of dilatation and curettage in Britain as compared with those in the United States; to examine variations in utilisation rates within one regional health authority.

Design-Analysis of routinely collected hospital inpatient statistics.

Setting-Statistics for England, Scotland, and the United States; local statistics for Oxford region.

Subjects-All inpatient episodes in which dilatation and curettage was performed but excluding those related to pregnancy.

Results-Dilatation and curettage rates remained stable in Britain between 1977 and 1990, whereas in the United States they declined dramatically. In $1989-90$ the rate was $71 \cdot 1$ per 10000 women in England as compared with only 10.8 per 10000 in America. In 1989, 6936 women underwent diagnostic dilatation and curettage in the Oxford region, making it the most common elective operation. $A$ total of $2726(39 \%)$ of these women were under 40 . There was a more than twofold variation in usage of the procedure among district health authorities within the region and even greater variation in rates in women under 40 . The proportion of patients treated as day cases in the district general hospitals ranged from $22 \%$ to $82 \%$.

Conclusions-Dilatation and curettage may frequently be used inappropriately. The considerable variations in usage of dilatation and curettage internationally and nationally indicate differences in clinical perception of its appropriateness. This makes it suitable for audit. In developing guidelines it will be important to agree on the most appropriate patients and the relative merits of alternative methods of endometrial sampling. Probably this could result in considerable cost savings at no risk and possibly some benefit to patients.

Health Services Research Unit, Department of Public Health and Primary Care, University of Oxford,

Radcliffe Infirmary, Oxford OX2 6HE

Angela Coulter, deputy

director

Anne Klassen, research officer

Nuffield Department of Obstetrics and

Gynaecology, University of Oxford, John Radcliffe Hospital, Oxford OX3 9DU

Ian Z MacKenzie, clinical reader

Department of Public Health and Policy, London School of Hygiene and Tropical Medicine, University of London, London WC1E 7HT

Klim McPherson, professor

of public health epidemiology

Correspondence to:

Ms Coulter. have generally reported high levels of patient acceptability, although some women experience pain and discomfort when undergoing these procedures. Dilatation and curettage carries a risk of complications including uterine perforation and laceration of the cervix. ${ }^{513}$

Rates of dilatation and curettage apparently fell by one third in the United States between 1979 and $1984 .^{30}$ We were interested to see whether gynaecological practice in Britain has changed in response to these critiques of dilatation and curettage and to compare rates of use of the procedure in Britain with those in the United States. To this end we examined national trends and conducted a detailed analysis of routine statistics on hospital admissions within the Oxford Regional Health Authority.

\section{Methods}

Dilatation and curettage is currently thought to be valuable for evacuating retained products of conception, so for this analysis we excluded pregnancy related procedures from all data sources.

Once a patient has had a hysterectomy she is no longer a potential candidate for dilatation and curettage. In order to see whether the international differences in patterns of use of dilatation and curettage could be due to changes in the numbers at risk for this reason we examined trends in hysterectomy rates in the United States and Britain.

\section{DATA SOURCES FOR ENGLAND}

Inpatient data for England were obtained from the Hospital In-Patient Enquiry for 1977 to $1985 .^{2}$ The data represent a one in 10 sample of discharges from all general hospitals. Before $1982^{\circ}$ the Hospital In-Patient Enquiry included both England and Wales, but from 1982 inpatient and day case episodes in Wales were excluded. Day case procedures were enumerated separately in this publication but we have added them to the inpatient data to maintain comparability with the other data sources. No national data for England were available for 1986 and 1987. In 1988 the Hospital InPatient Enquiry was replaced by the hospital episodes system, which aims to collect data on all hospital episodes. To date no national statistics have been published from this source. We obtained data for 198890 from the Department of Health. The figures from this source, which include day cases, were provisional estimates based on incomplete data which may be subject to revision pending ongoing analysis.

Inpatient admissions were coded by using Office of Population Censuses and Surveys procedure codes, third and fourth revisions. ${ }^{3132}$ For dilatation and curettage, codes 703 and 704 were used for 1977 to 1986 and code Q10 for 1987 to 1990 . Several different operations and diagnoses can be coded for each inpatient episode. The data collected for England represented numbers and rates of dilatation and curettage operations coded in the first position on an inpatient record, which is equivalent to the main operation for each episode. Office of Population Censuses and Surveys population estimates were used to calculate rates per 10000 women. We also obtained data on hysterectomy rates from the same sources by 
using codes 690-696 before 1987 and Q07 and Q08 after that date.

\section{DATA SOURCES FOR SCOTLAND}

Inpatient data for Scotland were obtained from Scottish Health Statistics for 1977 to 1990. ${ }^{33}$ These figures include day case procedures and, unlike the English statistics, incorporate dilatation and curettage and hysterectomy recorded at any point on the record, thus including those operations performed subsidiary to another procedure. Scottish data represent complete data collection from Scottish general hospitals. The coding systems used in Scotland are the same as those used in England. Female population based rates were calculated by using the population estimates published by the registrar general for Scotland.

\section{DATA SOURCES FOR UNITED STATES}

Inpatient data for the United States came from the National Center for Health Statistics through its national hospital discharge survey, which is a continuing nationwide sample survey of short stay, nonfederal general and specialty hospitals in the United States. ${ }^{34}$ The survey gathers information from patients' records in roughly a 5\% national sample of short stay hospitals. Data were obtained for numbers of all listed procedures for diagnostic dilatation and curettage operations, ICD-9-CM (ICD ninth revision, clinical modification) code $69.09^{35}$ (for 1977-8 these procedures were coded according to ICDA-8 (ICD eighth revision, adapted for use in the United States) code 70.3), including day case procedures. United States census data for the female civilian population were used to calculate population based rates. Hysterectomy rates were obtained from the same source using the ICD (seventh revision) classification for 1965-8 (codes 72.372.6), ICDA-8 from 1970 to 1978 (codes $69 \cdot 1-69 \cdot 5$ ), and ICD-9-CM from 1979 to 1990 (codes 68·3-68·7).

\section{DATA SOURCES FOR OXFORD REGION}

Inpatient data for the Oxford region were obtained from the Oxford Regional Health Authority corporate analysis department for the eight district health authorities in the region. Levels of clinical coding were very low in one district, which was therefore excluded from the analysis of trends. Good data became available in this district in 1990-1, and these have been used in the analysis of age specific rates and district variations described below. Data for 1979-86 came from Hospital Activity Analysis. The source for 1988 to 1990 was the regional information system. Statistics for all years included day case procedures and operations recorded at any point on the record. No data were available for 1987, the year after the recommendations of the Körner committee were implemented.

Data on district of treatment, age of patient, diagnosis at discharge, and length of stay were obtained for all patients on whom dilatation and curettage was performed during the 12 month period April 1989 to March 1990 for districts 1-7 and from April 1990 to March 1991 for district 8. On examination of the diagnoses at discharge it was apparent that a few $(n=272 ; 3.9 \%)$ of the dilatation and curettage operations coded Q10 were in fact performed for pregnancy related conditions. These were included in the analysis of trends to maintain comparability with the other data sources but excluded from the analysis of age specific and district rates. Office of Population Censuses and Surveys population estimates were used to calculate age specific rates for the region as a whole and for each health authority. Rates were standardised for age by using the indirect method. The completeness of the data was checked by examining the proportion of records of patients admitted to gynaecology in each district which had a clinical code.

\section{Results}

Figure 1 compares trends over time in dilatation and curettage rates for England (and Wales before 1982), the Oxford region, Scotland, and the United States between 1977 and 1989. The statistics for England exclude dilatation and curettage operations coded in the second or subsequent positions on a clinical record, whereas these are included in the statistics for Scotland, the Oxford region, and the United States. In 1989-90 the dilatation and curettage rate was $71 \cdot 1$ per 10000 women in England, 65.2 per 10000 in Scotland, and 56.6 per 10000 in the Oxford region (excluding district 8). In general, British rates had remained relatively stable during the period, in contrast with the dramatic decrease observed in the American hospitals, where rates had fallen from 88.7 per 10000 women in 1977 to $10 \cdot 8$ per 10000 in 1989 .

Trends in hysterectomy rates are shown in figure 2. In the United States the hysterectomy rate peaked in 1975 at 65.6 per 10000 women and subsequently decreased to 42.3 per 10000 in 1989 , paralleling the decrease in the dilatation and curettage rate. In contrast, the English, Scottish, and Oxford region hysterectomy rates showed a slight increase. Rates for 198990 were $30 \cdot 4,24 \cdot 2$, and $27 \cdot 1$ per 10000 respectively.

Table I shows the completeness of clinical coding for gynaecological admissions in each of the eight districts of the Oxford region. Completeness of clinical coding fell below $95 \%$ in districts 2,3 , and 4 , but in general these checks were reasonably reassuring.

Altogether 6936 diagnostic dilatation and curettage operations were performed in the Oxford region in 1989-90, making it the most common elective opera-

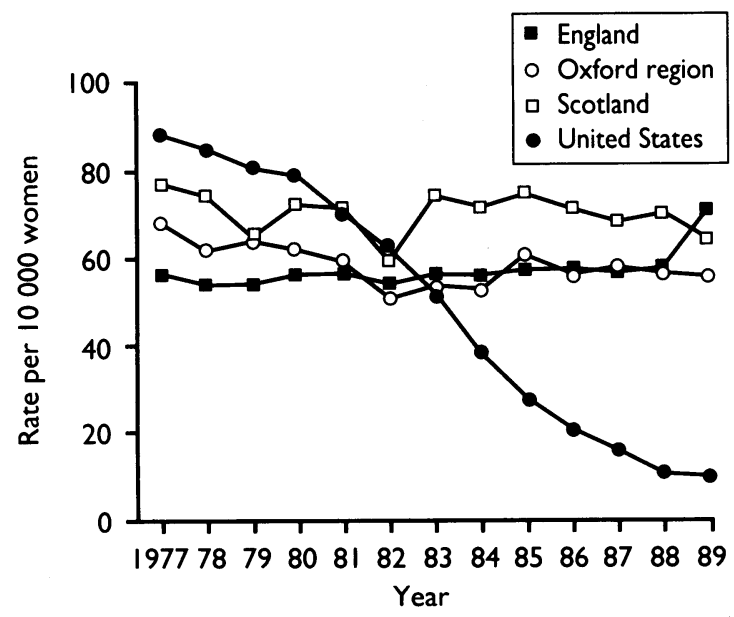

FIG 1-Trends over time in rates of dilatation and curettage in England and Wales (data for Wales before 1982 only), Oxford region, Scotland, and United States

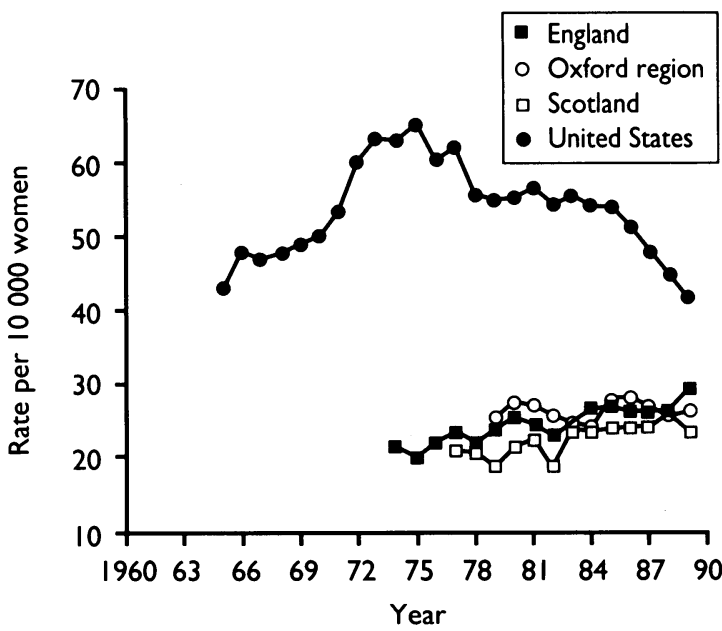

FIG 2-Trends over time in rates of hysterectomy in England and Wales (data for Wales before 1982 only), Oxford region, Scotland, and United States 
tion in the region. It was twice as common as hysterectomy, which was performed on 3490 patients. The age distribution of patients undergoing the procedure is shown in table II. Of the 6936 dilatation and curettage operations performed, 2726 (39\%) were on women aged under 40 .

The rate at which the operation was performed varied among the eight districts (table III). The rate in district 3 was $2 \cdot 7$ times the rate in district 1 . The rate of use for women under 40 also varied considerably, from 16.3 per 10000 in district $1(32 \%$ of the total in that district) to 58.6 per 10000 in district 3 (41\% of the district total). Table II also shows the proportion of dilatation and curettage operations performed as day cases in each district in the Oxford region. Only one district (district 6) was close to achieving the Audit Commission's target day case rate.

TABLE II-Age specific rates of dilatation and curettage in Oxford region

\begin{tabular}{lccccccccccc}
\hline & \multicolumn{11}{c}{ Age group (years) } \\
\cline { 2 - 11 } & $<20$ & $20-$ & $25-$ & $30-$ & $35-$ & $40-$ & $45-$ & $50-$ & $55-$ & $60-$ & $\geqslant 65$ \\
\hline Rate/10 000 women & 2.5 & 33.4 & 53.4 & 83.2 & 103.9 & 123.5 & 139.5 & 133.3 & 75.7 & 40.0 & 23.8 \\
\hline
\end{tabular}

TABLE III-Age standardised rates of dilatation and curettage per 10000 female population by district health authority, 1989-90; proportion of operations performed on women aged under 40; and proportion performed as day cases

\begin{tabular}{|c|c|c|c|c|c|c|}
\hline \multirow[b]{2}{*}{ District } & \multicolumn{2}{|c|}{ All women } & \multicolumn{2}{|c|}{ Young women } & \multicolumn{2}{|c|}{ Day cases } \\
\hline & No & Rate & No & $\%$ & No & $\%$ \\
\hline 1 & 808 & $29 \cdot 9$ & 260 & $32 \cdot 2$ & 465 & $57 \cdot 6$ \\
\hline 2 & 989 & $53 \cdot 4$ & 470 & $47 \cdot 5$ & 218 & $22 \cdot 0$ \\
\hline 3 & 1843 & 81.5 & 759 & $41 \cdot 2$ & 671 & $36 \cdot 4$ \\
\hline 4 & 649 & $45 \cdot 8$ & 177 & $27 \cdot 3$ & 423 & $65 \cdot 2$ \\
\hline 5 & 466 & $52 \cdot 3$ & 227 & $48 \cdot 7$ & 321 & 65.9 \\
\hline 6 & 887 & $67 \cdot 6$ & 348 & $39 \cdot 2$ & 725 & $81 \cdot 7$ \\
\hline 7 & 906 & $57 \cdot 2$ & 383 & $42 \cdot 3$ & 305 & $33 \cdot 7$ \\
\hline $8^{\star}$ & 388 & $50 \cdot 3$ & 102 & $26 \cdot 3$ & 237 & $61 \cdot 1$ \\
\hline Total & 6936 & $54 \cdot 3$ & 2726 & $39 \cdot 3$ & 3365 & $48 \cdot 5$ \\
\hline
\end{tabular}

\section{Discussion}

It is important to exercise caution when making international comparisons based on routine statistics. Different methods of data collection and different coding systems can lead to problems in interpretation. In particular there may be doubts about definitions and completeness of recording of day cases. Nevertheless, the differences between trends in use of dilatation and curettage in the United States and Britain are so dramatic that it seems unlikely that they are simply the result of inaccuracies in the data sources.

If the decrease in use of this procedure in the United States is not an artefact, then what has caused it? Unfortunately, in the United States as in Britain there are no national statistics on procedures performed in outpatient clinics, offices, or ambulatory centres. So, although it seems likely that American gynaecologists have switched to using the newer techniques for endometrial sampling, we cannot be certain that this is the case. In view of the greater use of unopposed oestrogen as a treatment for menopausal problems in the United States, with the consequent increased risk of endometrial cancer, it seems unlikely that American doctors have substantially reduced the rate of endometrial biopsies on perimenopausal or postmenopausal women. They do not seem to be using diagnostic laparoscopy as an alternative to dilatation and curettage, since rates of use of this procedure in the United States fell from $20 \cdot 2$ per 10000 women in 1980 to $9 \cdot 8$ per 10000 in $1989 .{ }^{36}$ The more likely explanation is that the increase in prospective payment schemes in the United States, which has put downward pressure on rates of use of elective inpatient surgery, has led them to favour the cheaper option of an outpatient procedure.

Interestingly, hysterectomy rates have also declined, although this operation is still performed at one and a half times the British rate. Clearly a woman who has had her uterus removed is no longer at risk of dilatation and curettage. In England the lifetime risk of hysterectomy is around $20 \%,{ }^{37}$ which means that true rates for dilatation and curettage among populations of women at risk would be roughly $25 \%$ (that is, $1 /(1-0 \cdot 2)$ ) higher than published population based rates. This is the rate which one would like to compare, and normally such adjustments are immaterial, but for dilatation and curettage and hysterectomy they could be crucial. The true adjustment depends, of course, on the relation of the age specific rates for the two operations. In the United States the lifetime risk, which is clearly a function of past hysterectomy rates as shown in figure 2 , has changed with time. It was estimated to be around $29 \%$ in 1970 and $43 \%$ by $1985 .{ }^{38}$ Thus the early part of the rates from dilatation and curettage in the United States in figure 1 are too low by around $41 \%$ and the latter part by around $75 \%$. Hence the eightfold reduction in rates in the United States can only partly be explained by this twofold adjustment for the true population at risk.

\section{SIMILAR INDICATIONS FOR TWO PROCEDURES}

Rates of use of these two operations are linked in another way since they are performed for similar indications, often on the same patients. Routine dilatation and curettage before hysterectomy used to be common in the United States but this is no longer considered necessary. ${ }^{15}$ Rates of use of most elective operations are much higher in the United States than in Britain, ${ }^{39}$ so it is particularly surprising to find that dilatation and curettage is performed more than six times more frequently in British hospitals. It is, however, possible that the observed decline in dilatation and curettage rates in American hospitals represents simply a change of setting from acute hospitals to independent ambulatory centres, which are not necessarily contributing data to the official statistics, but where day case dilatation and currettage may be being performed. Despite extensive inquiries we were unable to ascertain the extent to which dilatation and curettage, as opposed to the newer endometrial sampling techniques, was being carried out in ambulatory settings.

The differences between district health authorities in rates of use of dilatation and curettage were also dramatic. Variations within one region of Britain may be influenced by variations in levels of resources to a small extent, but they are more likely to be the result of variations in clinical judgment. ${ }^{40}$ General practitioners are known to differ in their propensity to refer patients to specialist outpatient clinics, and it is possible that some of the variation in dilatation and curettage rates observed here could be due to differing patterns of demand for specialist services. ${ }^{4 !}$ However, it is also obvious from these results that gynaecologists' styles of clinical practice differ. Anecdotal evidence suggests that specialists disagree on the desirability of using outpatient endometrial sampling procedures. It is clear that many continue to believe that it is appropriate to perform dilatation and curettage on younger women, despite the weight of published evidence arguing that this cannot be justified. It is also clear from our results that rates of use of day case surgery are very different between the districts. However, this example illustrates an important problem with the management emphasis on promoting day case surgery. Consultants with low use of day case dilatation and curettage who are instead using outpatient procedures rather than 
admitting patients will receive no credit for this good practice so long as management information systems exclude clinical data on outpatient activity.

The reasons for British gynaecologists' apparent reluctance to change, as compared with their American counterparts, are hard to establish. Possible explanations could include lack of financial incentives, lack of training in the new techniques, shortage of equipment, lack of suitable facilities, or unwillingness among patients to undergo outpatient procedures. It is also possible that British gynaecologists are unconvinced by the research evidence on the efficacy and acceptability of the new procedures. Certainly there is a dearth of scientifically sound randomised controlled trials which could settle areas of doubt and there is a strong case for more research in this area. However, in our view the explanation for the continuing high use of dilatation and curettage in Britain probably has more to do with the way in which outpatient clinics are currently organised, making it easier to place a patient on the waiting list for admission than to initiate diagnostic procedures in the clinic.

Based on the prices for inpatient and day case procedures quoted to general practitioner fundholders in each of the districts (an admittedly crude measure), we estimate that the dilatation and curettage operations carried out in the Oxford region cost around $£ 2 \mathrm{~m}$ at 1992 prices. A considerable part of this sum could be saved by reducing the number of investigations performed on younger women and resorting to outpatient procedures for most of the remainder. Since the rate of use of inpatient dilatation and curettage in the Oxford region is already lower than the national average, savings for the NHS as a whole could be considerable. Comparisons between inpatient curettage and outpatient procedures in the United States have calculated a 10 -fold reduction in costs. ${ }^{1942}$ Since it would seem that this saving could be achieved at no harm and possibly considerable benefit to patients, we recommend that gynaecology departments should consider current dilatation and curettage practice a priority for clinical audit. It will be interesting to see whether pressure from purchasers in Britain will have the same effect on dilatation and curettage utilisation rates as it has in the United States. Since current patterns of use lack scientific justification in terms of efficacy or efficiency, there would seem to be plenty of scope for rationalisation.

We are grateful to the locally organised research scheme of Oxford Regional Health Authority for supporting this study and to Sasha Shepperd for help in obtaining data from the United States.

1 Coulter A, Bradlow J, Agass M, Martin-Bates C, Tulloch A. Outcomes of referrals to gynaecology outpatient clinics for menstrual problems: an audit of general practice records. Br f Obstet Gynaecol 1991;98:789-96.

2 Department of Health, Office of Population Censuses and Surveys. Hospital inpatient enquiry 1985. London: HMSO, 1987. (Ser MB4.)

3 Audit Commission. A shon cut to better services: day surgery in England and Wales. London: HMSO, 1990.

4 Haynes P, Hodgson H, Anderson A, Turnbull A. Measurement of menstrual blood loss in patients complaining of menorrhagia. Br $\mathcal{F}$ Obstet Gynaecol 1977;84:763-8.

5 MacKenzie I, Bibby J. Critical assessment of dilatation and curettage of 1,029 women. Lancet 1978;ii:566-8.

6 Stock R, Kanbour A. Prehysterectomy curettage. Obstet Gynecol 1975;45: 537-41.
7 Danero S, Ricci M, La Rosa R, Massafra C, Franchi F, Potino C, et al. Critical review of dilatation and curettage in the diagnosis of malignant pathology of the endometrium. Eur F Gynecol Oncol 1986;7:162-5.

8 Gimpelson R, Rappold H. A comparative study between panoramic hysteroscopy with directed biopsies and dilatation and curettage. A review of 276 cases. Am f Obstet Gynecol 1988;158:489-92.

9 Brooks P, Serden S. Hysteroscopic findings after unsuccessful dilatation and curettage for abnormal uterine bleeding. Am $\mathcal{f}$ Obstet Gynecol 1988;158: curettage

10 Loffer F. Hysteroscopy with selective endometrial sampling compared with D\&C for abnormal uterine bleeding: the value of a negative hysteroscopic view. Obstet Gynecol 1989;73:16-20

11 Finikiotis G. Hysteroscopy: an analysis of 523 patients. Aust N Z $\mathcal{J}$ Obstet Gynaecol 1989;29:253-5.

2 Vessey $M$, Clarke J, MacKenzie I. Dilatation and curettage in young women. Health Bull 1979;39:59-62.

13 Smith J, Schulman H. Current dilatation and curettage practice: a need for revision. Obstet Gynecol 1985;65:516-8.

14 Hammond R, Oppenheimer L, Saunders P. Diagnostic role of dilatation and curettage in the management of abnormal premenopausal bleeding. Brf Obstet Gynaecol 1989;96:496-7.

15 Stovall T, Solomon S, Ling F. Endometrial sampling prior to hysterectomy. Obstet Gynecol 1989;73:405-9.

16 Webb M, Gaffey T. Outpatient diagnostic aspiration curettage. Obstet Gynecol 1976;47:239-41.

17 Gregg R. The praxiology of the office dilatation and curettage. Am $\mathcal{f}$ Obstet Gynecol 1981;140:179-85.

18 Valle R. Hysteroscopic evaluation of patients with abnormal uterine bleeding. Surg Gynecol Obstet 1981;153:521-6.

19 Grimes D. Diagnostic dilation and curettage: a reappraisal. Am 7 Obste Gynecol 1982;142:1-6.

20 Suarez R, Grimes D, Majmudar B, Benigno B. Diagnostic endometrial aspiration with the Karman cannula. $\mathcal{F}$ Reprod Med 1983;28:41-4.

21 MacKenzie I. Routine outpatient diagnostic uterine curettage using a flexible plastic aspiration curette. Br f Obstet Gynaecol 1985;92:1291-6.

22 Goldrath M, Sherman A. Office hysteroscopy and suction curettage: can we eliminate the hospital diagnostic dilatation and curettage? Am $\mathcal{f}$ Obstet Gynecol 1985;152:220-9.

23 Mencaglia L, Perino A, Hamon J. Hysteroscopy in perimenopausal and postmenopausal women with abnormal uterine bleeding. I Reprod Med postmenopausal

24 Lofgren O, Alm P, Ionescu A, Skjerris J. Uterine microcurettage with combined endometrial histopathology and cytology. Acta Obstet Gynecol Scand 1988;67:401-3.

25 Lewis BV. Hysteroscopy for the investigation of abnormal uterine bleeding. Br f Obstet Gynaecol 1990;97:283-4.

26 De Jong P, Doel F, Falconer A. Outpatient diagnostic hysteroscopy. Brf Obstet Gynaecol 1990;97:299-303.

27 Fraser I. Hysteroscopy and laparoscopy in women with menorrhagia. Am $\mathcal{F}$ Obstet Gynecol 1990;162:1264-9.

28 Eddowes H. Pipelle: a more acceptable technique for outpatient endometrial biopsy. Br f Obstet Gynaecol 1990;97:961-2.

29 Stovall T, Ling F, Morgan P. A prospective randomized comparison of the Pipelle endometrial sampling device with the Novak curette. Am $\mathcal{f}$ Obstet Pipelle endometrial sampling
Gynecol 1991;165:1287-9.

30 Grimes D. Declining surgical case-load of the obstetrician-gynecologist. Obstet Gynecol 1986;67:760-2.

31 Office of Population Censuses and Surveys. Classification of surgical operations. London: HMSO, 1975.

32 Office of Population Censuses and Surveys. Tabular list of the classification of surgical operations and procedures. Fourth revision. London: HMSO, 1990.

33 Information and Statistics Division, Common Services Agency for the Scottish Health Service. Scottish health statistics. Edinburgh: Common Services Agency, 1990.

34 National Center for Health Statistics. National hospital discharge survey. Hyattsville, Maryland: US Department of Health and Human Services, 1982-91. (Series 13.)

35 World Health Organisation. International classification of diseases. Manual of the international statistical classification of diseases, injuries and causes of death. international statistical classification

Ninth revision. Geneva: WHO, 1978 .
36 National Center for Health Statistics. Health, United States, 1990. Hyattsville, Maryland: Public Health Service, 1991.

37 Vessey M, Villard-Mackintosh L, McPherson K, Coulter A, Yeates D. The epidemiology of hysterectomy: findings in a large cohort study. Br $\mathrm{f}$ Obstet Gynaecol 1992;99:402-7.

38 National Center for Health Statistics. Hysterectomies in the United States, 1965-84. Hyattsville, Maryland: US Department of Health and Human Services, 1987. (Vital and Health Statistics, ser 13, No 92.)

39 McPherson K, Strong P, Epstein A, Jones L. Regional variations in the use of common surgical procedures: within and between England and Wales, Canada and the United States of America. Soc Sci Med 1981;15:273-88.

40 Coulter A, McPherson K, Vessey M. Do British women undergo too many or too few hysterectomies? Soc Sci Med 1988;27:987-94.

41 Coulter A, Seagroatt V, McPherson K. Relation between general practices' outpatient referral rates and rates of elective admission to hospital. $B M \mathcal{F}$ 1990;301:273-5.

42 Lutz $M$, Underwood P, Kreutner A, Mitchell K. Vacuum aspiration: an efficient outpatient screening technic for endometrial disease. South Med $\mathcal{J}$ 1977;70:393-7.

(Accepted 17 November 1992) 